\title{
THE DESIGN AND CONSTRUCTION OF THE VLA: THE PROJECT MANAGER'S VIEW
}

JOHN H. LANCASTER

\section{INTRODUCTION}

Thank you for the invitation to talk to this distinguished group. I want to talk of the items that would make Projects like the VLA successful in the future and then go on to some specifics concerning the Very Large Array Construction. Just recently a boating friend said, "Your talk should be like a woman's skirt; long enough to cover the essentials, but short enough to be interesting". Let's hope it is.

\section{PREREQUISITES FOR SUCCESS}

To succeed, a project must have have a number of specific attributes:

\section{The Program or Project}

- Must have a sound scientific basis.

- Should be a quantum jump over existing capabilities.

- Must have wide and active support from the scientific community.

- Must have sufficient basic investigation done to ensure that the concepts, proposed solutions and cost estimates are reliable.

- Can not be so expensive that it will choke off all other research in its discipline.

\section{Sponsoring Organization}

- Must be widely based, highly regarded and experienced.

- Must be able and willing to bring scientific, political, media, and business pressure to bear.

- Must be interested in the long pull and willing to help with problems.

- Must be willing to let the Project Management Group stand on its own feet, rather than insist that financial, business, procurement, and possibly other matters be controlled by central authority not directly under the Project Manager's control.

\section{Financing Agency}

- Must be intensely interested and willing to carry the Project thru the Administration and Congress.

- Must have adequate organization and financial capability. 
- Must not insist on micro-managing the Project.

- Must appoint a single official as contact. One who has sufficient authority to keep reviews, approvals, etc. moving thru the agency. Required reports should be kept to the bare minimum and be meaningful. Periodic oversight reviews and audits are necessary, but as they are very time consuming they should be held to a minimum.

\section{Project Management}

Must have one person in complete charge, able to delegate as necessary. That person, or his designee, should report periodically up the line. Should have Advisory Committees, but none in the line of command. Project Organization must be simple with no more than four levels from the top to the technician doing the work. Access to all levels of management should be open to all employees.

\section{THE VLA PROJECT}

How did the VLA project measure up?

\section{Scientific Programs}

The VLA Program was outstanding in all categories.

\section{The Sponsoring Organization}

Associated Universities Incorporated was the first of the multi-university scientific organizations, and of course we believe still the best.

\section{The Financing Agency}

The National Science Foundation gets high marks in all categories, except in the level of funding necessary to effect the best and lowest cost Project. With the optimum funding level it was estimated that the VLA could have been completed at a saving of over twelve million dollars. We of course must recognize that the Congress has much to do with the funding levels, and when one considers all of the pressures the Foundation was under, they did rather well for the VLA.

\section{The VLA Project Management}

Dave Heeschen was the man in charge and is as fine a manager and person as I have ever known.

In all other categories the Project did well although we did have a few arguments as to whom the fiscal, business and procurement people were responsible.

Now that the humdrum is out of the way let us move on to other requirements for successful Project management.

\section{OTHER REQUIREMENTS}

Willingness to take calculated risks

Much of the VLA design was on the forefront including the waveguide data transmission system. Bell Laboratories had done most of the development 
work and recommended burial of the waveguide inside a heavy wall steel tube. This would have doubled the cost of the $\$ 6.6$ million system. A number of burial tests were performed without the outer steel casing, they were successful, direct burial was used and it worked.

\section{Guts or the willingness to fight}

After three years and the successful completion of two railroad construction contracts, the Davis-Bacon people of the US Department of Labor arbitrarily decided to nearly double the wage rates the Project would have to pay to the construction workers. This would have increased the cost of the Wye by about $\$ 2.5$ million or eliminated the A array. With the full backing of AUI and NSF the decision was appealed in the courts and reversed. This delayed the Wye by eighteen months, but the funds set aside for this use were used effectively elsewhere.

Late in the Project the State of New Mexico decided to assess a $4 \%$ New Mexico State Gross Receipts tax on the antennas, with the probability that the assessment would spread to other parts of the Project. We again went to litigation with the US Department of Justice handling the case, and again won after a twenty minute period of deliberation by a federal judge.

\section{Adequate advance financing}

This was mentioned earlier but I would like to give two examples:

As funding was not available, the contract for the parametric amplifiers covered only a small number of units with follow-on options for later years. The first year the company produced satisfactorily. The second year they had trouble and by the third year they had lost the key engineers, technicians and sources of supply and just could not make satisfactory units. One year before Dedication we were faced with the horrifying outlook that we would have only sixteen or seventeen antennas on line instead of twenty-seven. Fortunately NRAO developed the GaAs FET amplifier in time to save the Project.

The waveguide had to be ordered under four contracts due to financial restraints. The first waveguide was purchased for $\$ 44$ per meter and the last for $\$ 79$ per meter. A possible saving of $\$ 2.2$ million.

\section{Good negotiation skills}

The VLA had many good negotiations but the best was the Antenna contract. As funds were not available this contract had to have seven options calling for production over the years. Three days after the execution of the fixed-price contract the OPEC oil embargo struck and soon the price of steel had doubled. In June 1976 the Contractor refused to proceed with fabrication of antennas 7 thru 10, arguing that their losses were too great, and they were excused by the provisions of the Uniform Commercial Code. Ted Riffe and I acted for NRAO and the President and Chief Fiscal Officer acted for the Contractor. The negotiation lasted almost a week and it was like watching grass grow. Ted would talk about sports, the weather, the political situation and once per hour state that the Contractor was honor bound to contract or else we would have to black list him. We didn't know whether we could blacklist him with DoD, but it sounded good. The Contractor would quote his horrendous losses. Then back to idle chatter for another hour and repeat statements. It must have been 
very similar to a diplomatic negotiation. After four days of this every one was sick and tired and a deal was struck in three hours.

A second good negotiation was with the local utility company which resulted in their building a 26 -mile mile long high voltage transmission line, including switchgear and substation, dedicated only to the VLA, at a cost to the Utility of $\$ 450,000$.

\section{A big man at the top}

Every Project needs a big man at the top. After reaching agreement with the Antenna Contractor I went to NSF and tried my best to sell the deal to all involved. Apparently I did not do well, as at the final conference before the big boss everyone that I had talked to had copious notes. I presented my case, and all around the table the staff leaned forward bringing into position their notes. Then the boss said "Well, that sounds like a good deal to me and if none of you have any objections lets approve it and get back to work". There was a collective sigh around the table, but no one objected. The big man was Bob Hughes.

\section{Flexibility}

The early VLA reports estimated that used rail could be purchased for $\$ 90$ per ton and about 14,000 tons would be required. By 1973 the cost had soared to over $\$ 250$ per ton and at one point reached $\$ 330$ per ton Direct purchase would have resulted in about a $\$ 2$ million over-run. With NSF's active support we searched out every possible source of excess Government railroad rail and brought it to the VLA. Twenty eight sites, from coast to coast, were cleaned out and our final cost was $\$ 53$ per ton. This action changed a major over-run into an under-run of half a million dollars.

When procurement timing depends upon satisfactory completion of complex designs a Project must be ready to move on alternate paths if that design completion is delayed. We were usually ready to move in three or four directions whenever funds became available.

Luck

All successful Projects have to be lucky. Our largest piece of "luck" was the change of the US fiscal year in 1977 which gave us an unexpected $\$ 3.5$ million which undoubtedly saved the antenna contract and gave the Project a big boost.

\section{Geniuses}

Projects should have a few geniuses about. We had many but I will only mention two:

SANDY WEINREB: Sandy not only did most of the System Design for the VLA electronics but when the parametric amplifier fiasco came along he was instrumental in the development of the cryogenic GaAs FET which saved the Project schedule.

BARRY CLARK: During the conceptual design of the VLA a number of the large computer companies were approached to estimate the cost of the required computers and software. These estimates were in the tens of millions of dollars. This kind of money just was not available so NRAO decided to tackle the job in-house. Barry and Bob Hjellming took on the task with a 
budget of $\$ 5.3$ million. Barry took over complete responsibility in late 1976 and completed the construction phase at a cost of $\$ 6.4$ million.

I have heard that David Packard once said that if he had wanted to stop the VLA dead in it's tracks, all he had to do was to hire Sandy and Barry.

\section{Unexpected surprises}

Every Project must be ready for the unexpected.

The Project was under constant review by the staffs of various

Committees of the Congress. In March of 1976, after a long investigation, one formal Staff report stated in conclusion "The ommittee is very pleased with the close agreement between the original and current budget and time schedules and commends the project's accomplishments to date". Then strangely in summary it continued " Therefore, the Committee strongly recommends that ... a panel be selected ... to examine VLA management and technical plans and activities and report findings and recommendations". The panel was appointed and twenty one months later, after many man hours of effort and at a cost of $\$ 17,000$ to the Project, it was completed. The Panel's report was very complementary to the Project.

In late 1975 when NRAO was installing the feed systems for Antenna \#1 the technicians were rocked by supersonic flights of $F$-111s using radar terrain flight systems. Peter Napier quickly calculated that if one was at the prime focus at that time, it was probable that ruptured ear drums would result. I geared up to take on the US Air Force and DoD, anticipating great difficulties, when a letter suddenly arrived from the Colonel in charge of the flights asking whether we would like him to have the flight path changed.

\section{Management items}

The success of the VLA was largely due to the Monday Coordination Meetings. These were held the first thing Monday morning at the site and attended by all Group Leaders. Few excuses were accepted for absence. All scheduled items were thoroughly discussed, delays adjusted and cost over-runs made known. By having all Groups represented by its top man it was usually possible to settle most problems on the spot.

We made little use of CPM and none of PERT. The Project was not so large that staff could be spared to make up the detailed estimates of progress and cost necessary for a workable system. It was also found that a knowledgeable coordinator working quietly with the groups would get more trustworthy data and could then make realistic schedules. We were very lucky to have Bob Mitchell to do this.

All Projects have problems obtaining timely reviews and approvals. We solved this by the "Friday Letters". Each Friday I would send the Foundation a letter listing any late items and the date submitted. If everything was on schedule the letter would so state. Of course many copies were sent to various levels of management. I must have been told a dozen times to stop these letters, but never by my boss.

\section{Friends}

All Projects need good friends and the VLA had many. Among them come to mind Senator Domenici, Representative Lujan, and Governor King, but one couple I would like to single out: 
Jack and Grace Bruton

The Bruton's owned the central 640 acre tract on which all the VLA buildings are constructed. They actively supported the Project in every way. Without their cooperation the construction would have been much more difficult and probably more time consuming. We took possession of this tract in 1973. I recently heard that they even paid real estate taxes on this section until about 1988. It is fortunate that they didn't foreclose. They hoped that the construction of the VLA would keep the local young people from leaving the area. I hope that this goal has been achieved.

\section{People}

Of course the most important component of any Project is the people who are doing the work. In this area we were extremely fortunate and at all times had very capable, dedicated personal. During the nine years that the Project ran we hired 335 people, but never had more than 133 on board at any time. I can only mention a few of the people here, and probably anger many, for which I apologize.

BILL HORNE was in charge of all Antenna and Transporter work. His group reviewed all then existing antennas and calculated the elbow where cost rapidly increased when surface accuracy increased slightly. The VLA specifications were aimed at this point and the antennas turned out far better than expected.

FORREST WELLS was in charge of all conventional construction. A tried and true method of analyzing the effectiveness of the design, bidding and construction of facilities is the percentage cost of change orders required to properly complete the work. Five percent is good, ten percent shows sloppy design, specifications or construction. Forrest's percentage was one half of one percent.

NOW, WILL ALL THOSE WHO HAD A HAND IN THE PLANNING, DESIGN, OR CONSTRUCTION OF THE VLA PLEASE STAND. THIS MEANS THOSE STATIONED IN WASHINGTON, CHARLOTTESVILLE, GREEN BANK OR SOCORRO.

These are the people who made the VLA the success it is and I consider it a great honor to have been a part of this group. 